\title{
COMPARISON OF BONE HEALING AFTER THE USE OF A THREE DIMENSIONAL MINIPLATE AND A CONVENTIONAL MINIPLATE IN MANDIBULAR BODY OSTEOTOMY (AN EXPERIMENTAL STUDY)
}

\author{
Mohamed M. Elrewany ${ }^{1 *} B D S$, Ragab S. Hassan ${ }^{2} P h D$, Ziad T. Mahmoud ${ }^{3} P h D$, \\ Dina A. Nagui ${ }^{4} P h D$
}

\begin{abstract}
INTRODUCTION: Mandibular fractures comprise most of the traumatic injuries treated by an oral and maxillofacial surgeon. The aim of fracture treatment is to restore the architecture and function of bone. Many techniques for treating mandibular fractures have evolved over the years. The design of the three dimensional (3D) plate is conceptually that of 2 linear plates connected by reinforcing vertical struts providing greater resistance against gap opening at the inferior border with biting forces.

OBJECTIVES: To compare histologically bone healing of mandibular body osteotomy after using either a 3D miniplate or conventional miniplates.

MATERIALS AND METHODS: This study was conducted on twelve healthy dogs. An iatrogenic osteotomy defect was performed intraorally between the mandibular 3rd and 4th premolars using a surgical micro reciprocating saw. The fragments will be reduced bimanually and stabilized:

Group A (six dogs): 3D miniplates.

Group B (six dogs): conventional miniplates.

The dogs were euthanized at 2 and 6 weeks postoperatively and the osteotomy sites were excised, divided into three thirds (Tension Third, TT; Intermediary Third, IT; Compression Third, CT) and prepared for histological analysis.

RESULTS: The osteotomy site was completely filled with parallel-fibred bone, with more newly formed Haversian systems in Group A compared with Group B, bone repair did not reach the typical aspects of the parent lamellar bone. The percentages of newly formed bone at 2 weeks in group A according to thirds (TT, IT and CT) that reported have a statistically significant difference in comparison with group B. At 6 weeks, there were no statistically significant differences between the two groups among the TT and CT but there was a statistically significant difference $(\mathrm{p} 4=0.039)$ in the IT.
\end{abstract}

CONCLUSIONS: 3-D plates could be a better option than conventional miniplates.

KEYWORDS: Mandibular fracture, 3-D plates, osteosynthesis, conventional miniplates.

1- BDS, Faculty of Dentistry, Alexandria University.

2- Professor of Oral and Maxillofacial Surgery, Faculty of Dentistry, Alexandria University.

3- Lecturer of Oral and Maxillofacial Surgery, Faculty of Dentistry, Alexandria University.

4- Lecturer of Oral Biology, Faculty of Dentistry, Alexandria University.

*Corresponding author:

E-mail: melrewany69@yahoo.com

\section{INTRODUCTION}

The mandible is frequently fractured because of its prominence, where it occupies a central and vulnerable position in the face. Its architecture is complex, consisting of an articulation with the cranial base, making it the only freely movable bone of the facial skeleton. It is subjected to strong biomechanical distractions by its intimate association with the facial musculature (1)

Concept of rigid fixation: Spiessl (2) introduced compression plates, which were fixed along the lower border of fractured mandible using bicortical screws. Compression plates rigidly fixed the fractured bone segments sufficiently to prevent inter-fragmentary movement and provide healing by primary intention. Difficulty in adaptation, bulk of the plates, scar formation due to extraoral approach, and increased chances of nerve injury were their disadvantages.

Concept of semi-rigid fixation: Champy et al., (3) defined the "ideal lines of osteosynthesis". Champy revolutionized intraoral fixation by innovating and modifying the Michelet et al.'s (4) technique of osteosynthesis. It consisted of monocortical, juxta alveolar, and subapical osteosynthesis without compression and intermaxillary fixation using miniaturized malleable plates. Small size of the plate, easy adaptability, easy placement, and use of intraoral approach led to increased use of monocortical plates in maxillofacial surgery (5).

Farmand and Dupoirieux (6) presented 3D plates with quadrangular shape formed by joining two miniplates with interconnecting crossbars. Because of the quadrangular configuration of the plates, they provided good stability and resistance to torsional forces. Easy use, good resistance against torque forces, and compact form of the plates were some of their advantages (7).

Unlike compression and reconstruction plates, the stability of 3D plates does not derive from the thickness of the plate. In combination with the screws monocortically fixed to the outer corticalis, the rectangular plate forms a cuboid, which possesses 3D stability (8). Another advantage of 3D plates is their improved biomechanical stability compared with conventional miniplates (9). 
Another biomechanical study has been performed by Kalfarentzos et al in the year 2009 (10) to evaluate the effectiveness of the 3D square plate along with three other mandibular plating techniques. They have reached to the conclusion that the 3D square plate system provided the most favorable mechanical behavior. In addition, the use of a square-shaped $2.0 \mathrm{~mm} 3 \mathrm{D}$ plate, properly contoured as described, seems to have optimal biomechanical behavior in simulated bending and torsional forces (11).

Well designed in vivo animal models continue to play an important role in helping to understand the mechanisms of mechanical intervention in healing and tissue engineered bone formation, where it enables us to assess the quality of the regenerate and the viability of the treatment method, an advantage that human studies cannot offer (12).

Dogs are one of the more frequently used large animal species for musculoskeletal and dental research (13). Unlike other animal species, there is a considerable amount of literature comparing canine and human bone with regard to the usefulness of the dog as a model in researches involving human bone $(14,15)$. This study aimed to compare histologically bone healing of mandibular body osteotomy after using either a three dimensional miniplate or conventional miniplates.

\section{MATERIALS AND METHODS}

\section{I.Materials}

\section{A. Plates and screws for internal fixation}

Two types of plates (KLS Martin Group, Tuttlingen, Germany) were used for fixation of the complete osteotomy defect.

\section{Group A: (six dogs)}

Double square 3D titanium miniplates of $1.0 \mathrm{~mm}$ thickness (3 $x 2$ holes interconnected by vertical struts) fixed with 2.0 $\mathrm{mm}$ titanium miniscrews of $7 \mathrm{~mm}$ length.

Group B: (six dogs)

Two 4 holes conventional miniplates fixed with four 2.0 $\mathrm{mm}$ miniscrews of $7 \mathrm{~mm}$ length for each plate using Champy's principles of osteosynthesis.

\section{B. Experimental animals}

The study was performed after obtaining the approval of the Research Ethics Committee, Faculty of Dentistry, Alexandria University.

The study that was conducted on 12 male adult dogs weighing 10-25 kilograms, six dogs in each group. Animals were kept under the same nutritional and environmental conditions throughout the whole period of the study in the animal house at the Department of Surgery, Faculty of Veterinary Medicine, Alexandria University.

\section{II.Methods}

\section{Pre-operative care}

- All the dogs were kept under the same nutritional and environmental conditions throughout the whole period of the study.

- All dogs were examined for their overall general health.

- All dogs were kept on the same diet throughout the whole period of the study.

- Each dog was weighed to estimate the amount of anesthetic solution.

- All the dogs were kept fasting the night before operation.

\section{Surgical procedures}

\section{A. Anesthesia}

All operating procedures were performed under the effect of sedation and general anesthesia. Sedation was performed by IM injection of Xylazine Hcl (Xyla-Ject, Adwia Pharmaceuticals, 10th of Ramadan City Industrial Area, Egypt) $1 \mathrm{mg} / \mathrm{kg}$, followed by induction of anesthesia using Ketamine Hcl (Ketamine, Sigma Pharmaceutical Industries, Nasr City, Cairo, Egypt) 10mg/kg IM. Anesthesia was maintained by IM injections of Xylazine $\mathrm{HCl} 1 \mathrm{mg} / \mathrm{kg}$ and Ketamine $\mathrm{HCl} 5 \mathrm{mg} / \mathrm{kg}$.

\section{B. Surgical Operation}

The surgical procedure was performed under aseptic conditions for all animals.

Each animal received $1 \mathrm{gm}$ received cefotaxime broad spectrum antibiotic (Cefotax, EPICO Pharmaceuticals, 10th of Ramadan City, Egypt) (1gm IM injection) as a prophylactic measure.

The animals were placed in a lateral recumbent position. The surgical sites were painted with Povidoneiodine solution u.s.p 10\% w/v (Betadine, NILE Company for Pharmaceutical and Chemical Industries, Cairo, Egypt.), followed by the administration of local anesthesia [Mepivacaine hydrochloride U.S.P. $20 \mathrm{mg}$ (2\%) + Levonordefrin hydrochloride $0.06 \mathrm{mg}$ (Mepecaine - L, Alexandria Co. for Pharmaceuticals, Egypt)] for the purpose of hemostasis.

An iatrogenic osteotomy was performed between the mandibular 3rd and 4th premolars through an intra-oral approach using Bard Parker scalpel handle no.3 and a disposable blade no.15. The flap was then reflected through careful sharp dissection then the periosteum was completely removed to expose the bone. Using a low speed motor, surgical micro-reciprocating saw and the surgical blade was positioned perpendicular to the mandibular body and a complete defect was created.

Fixation of the complete defect was done as follows:

\section{In Group A:}

The fragments were reduced bimanually for proper anatomical position and stabilized in accordance with the principles of the AO (16) for transverse fracture line without dislocation by the 3D titanium miniplates.

The 3D plate was placed in the way as described by Farmand and Dupoirieux, in which the horizontal bars were perpendicular to fracture line and vertical ones were parallel to it (Figure 1).

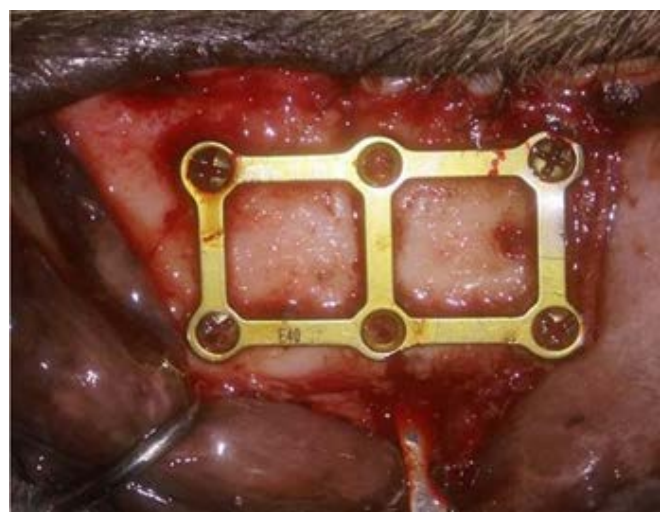

Figure (1): A photograph showing the fixation with a 3D titanium miniplate.

The plate was adapted at the lower border of the mandible. The upper crossbar of 3D plates was placed in 
sub apical position of teeth, and injury to dental roots was avoided using mono-cortical screws. The lower border of the plate was fixed at first by two 2.0 miniscrews then the two peripheral holes of the upper border of the plate by two 2.0 miniscrews using a drill on a straight hand piece cooled externally with a syringe containing saline solution.

\section{In Group B:}

The fragments were stabilized by two 4 holes conventional miniplates along the osteosynthesis lines as described by Champy (Figure 2).

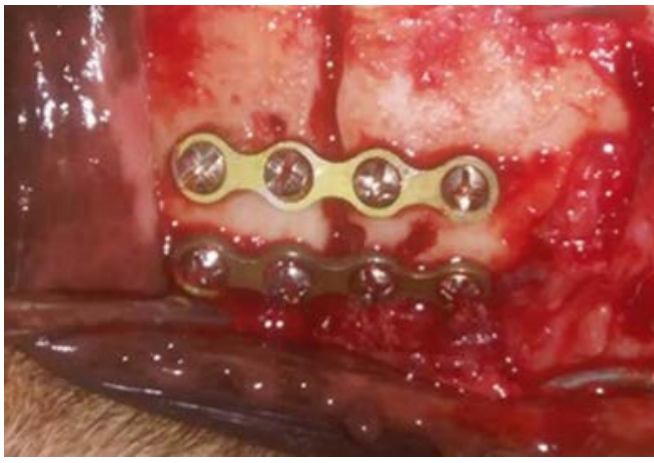

Figure (2): A photograph showing the fixation with two conventional miniplates

The first plate was adapted at the lower border of the mandible, fixed by four $2.0 \mathrm{~mm}$ miniscrews using a drill on a straight hand piece cooled externally with a syringe containing saline solution for constant irrigation. The second plate was adapted and fixed with four miniscrews.

\section{Suturing:}

The wound was abundantly irrigated with saline solution and closed using absorbable suture polyglycolicpolylactic 4-0 suture material (Vicryl, Ethicon, Cornelia, GA, USA).

\section{Postoperative care}

- All the dogs received the same course of antibiotic and antiinflammatory drugs for the following postoperative 3 days in the form of Cefotaxime (Cefotax, EPICO Pharmaceuticals, 10th of Ramadan city, Egypt) 1gm IM injection every 12 hours and $1 \mathrm{ml}$ Piroxicam (Feldene, Pfizer Egypt, Dokki, Giza, Egypt) 20mg/ml IM injection every 8 hours.

- Animals were kept on a soft diet during the first postoperative week then returned to their normal food.

- Animals were kept under observation for the whole experimental period to assess the presence or absence of any sign of infection or wound dehiscence.

\section{Animal scarification}

Dogs were euthanized at 2 and 6 weeks postoperatively, six dogs at a time, three dog from each group, with an intravenous injection of one-shot thiopental sodium.

Segments of the mandibular body were resected close to the plates and were retrieved to be prepared for histological examination. They were immediately fixed in $10 \%$ neutral buffered formalin for two weeks (17).

\section{Preparation of the Histological Sections}

Following fixation, the specimens were decalcified for 6-8 weeks in $8 \%$ trichloroacetic acid, then washed under running water and dehydrated in ascending grades of ethyl alcohol.

Decalcified specimens from the osteotomy site and the adjacent bone were divided into three equal parts. The upper part that included the crest of the alveolar process was labelled the tension third (TT), the lower part that included the mandibular base was labelled the compression third (CT), and the part between the TT and CT was labelled the intermediary third (IT). For each specimen, the upper site of each part was oriented horizontally and embedded in paraffin.

Specimens were then infiltrated by melted paraffin wax then embedded in a block of paraffin wax to be sectioned in a mesiodistal direction. Then, sections were cut at 4 microns thickness using rotatory microtome and stained with Haematoxylin \& Eosin (H\&E) stain for light microscopic analysis (LM).

\section{Histomorphometric evaluation}

Morphometric evaluation of the area percentage of the newly-formed bone (18) was assessed for each specimen using the (Image $\mathrm{J}$ 1.46) program by using the thresholding method $(19,20)$.

- Photographs were taken from each third (TT, IT and CT) using the same magnification power (100x).

- Measurements were obtained from each photograph, and then the mean values were calculated.

\section{Statistical Analysis}

Data were fed to the computer and analyzed using IBM SPSS software package version 20.0. (Armonk, NY: IBM Corp (21). Quantitative data were described using range (minimum and maximum), mean, standard deviation and median. Significance of the obtained results was judged at the $5 \%$ level (22).

\section{The used tests were:}

\section{1-Student t-test}

For normally distributed quantitative variables, to compare between two studied groups.

\section{2-ANOVA with repeated measures}

For normally distributed quantitative variables, to compare between more than two periods or stages, and Post Hoc test for pairwise comparisons.

\section{RESULTS}

\section{Clinical Results}

All animals survived very well, no signs of inflammation or infection were noted. The whole experimental period went without complications.

\section{Histological Results:}

\section{The first experimental period (Two weeks postoperatively): \\ Group A:}

TT: The osteotomy site exhibited dense granulation tissue characterized by an increased amount of collagen fibers. The gap created by the osteotomy showed deposition of discrete islands of woven bone within the fibrous tissue. There was a remarkable inflammatory cells infiltrate (Figure3A).

IT: Borders of the fracture line showed condensation of dense fibrous tissue containing blood vessels, with minute immature bone deposits within the collagen fibers (Figure 3B).

CT: The histological findings were similar to those observed for the IT, with exception for the endosteal reaction, which showed heavier amounts of connective tissue and inflammatory cells. Areas of immature bone deposition along the borders of osteotomy site were detected. Nevertheless, as observed for the TT, the bone discontinuity was still present, indicating the absence of complete bone repair at the osteotomy site (Figure 3C). 


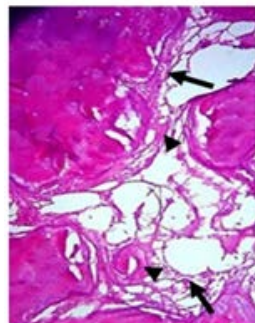

A

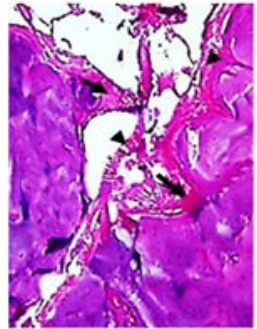

B

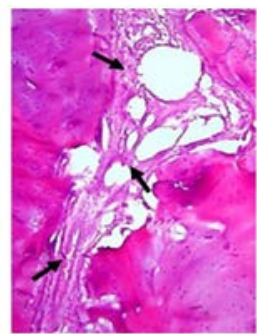

C
Figure 3:(A) L.M of Group A after 2 weeks (TT) showing heavy amount of granulation tissue (arrows) intermingled with bone deposits (arrowheads). (H\&E, x100). (B) L.M of Group A after 2 weeks (IT) showing peripheral immature bone deposits (arrows). Note the enclosed areas of fibrous tissue rich in blood vessels (arrowheads). (H\&E, x100). (C) L.M of Group A after 2 weeks (CT) showing immature bone formation. Note the little amount of fibrous tissue contained within the osteotomy site (arrows). (H\&E, x100)

\section{Group B:}

TT: The osteotomy gap was filled with loose connective tissue with moderate inflammatory reaction. Blood vessels were scattered among the fibers (Figure 4A).

IT: Increased density of vascularized fibrous tissue along the osteotomy site was detected. However, minute bone deposits could be noticed within the granulation tissue along the fracture site (Figure 4B).

Adjacent to the osteotomy site at CT, The osteotomy site and the medullary area showed dense connective tissue with focal areas of inflammatory infiltrate and blood vessels. Whereas, discrete areas of newly formed woven bone along the periphery of the fracture line were seen. This newly deposited bone was separated from the native bone by a dense remodeling line (Figure 4C).

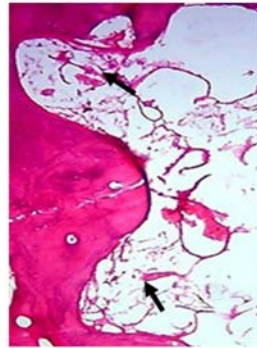

A

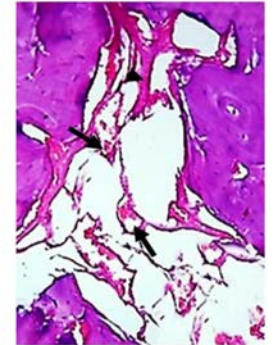

B

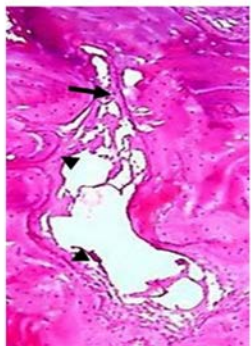

C
Figure (4): (A) L.M of Group B after 2 weeks (TT) showing noticeable amount of granulation tissue with limited number of blood vessels (arrows). (H\&E, x100). (B) L.M of Group B after 2 weeks (IT) showing large areas of fibrous tissue rich in blood vessels (arrows). Note the minute deposits of immature bone along the collagen fibers (arrowhead). (H\&E, x100). (C) L.M of Group B after 2 weeks (CT) showing condensed fibrous tissue with inflammatory cells still contained within the fracture line (arrow). Minimal woven bone deposition along the osteotomy line were found delineated by a remodeling line between it and old bone (arrowheads). (H\&E, x100)

\section{The second experimental period (Six weeks} postoperatively):

\section{Group A:}

TT: The zone of fracture was completely filled with large areas of woven bone intermingled with few islands of mature lamellar bone. The immature bone was by characterized by numerous, irregularly arranged osteocytes. The interface between the lamellar bone and the newly formed bone was indistinct. However, few areas of vascularized connective tissue were still noted (Figure 5A).
IT: The amount of bone formed, and the relative proportion of the woven immature bone to the mature bone filling the gap was intermediate between the TT and CT (Figure 5B).

CT: Although the osteotomy site was completely filled with fine-fibred woven bone, with more definite newly formed Haversian systems compared with TT, such a stage of bone repair did not reach the typical aspects of the parent, lamellar bone (Figure. 5C).
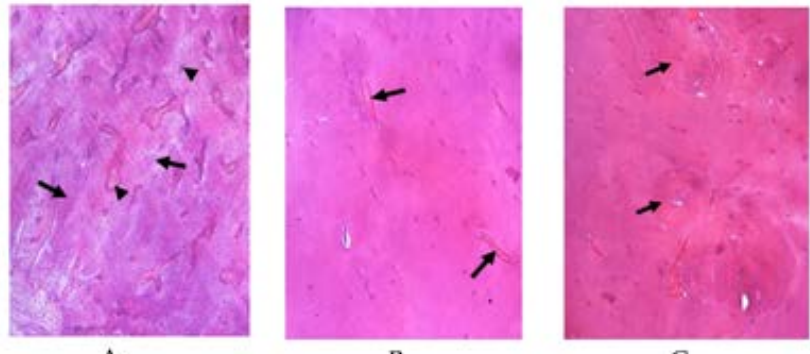

B

C

Figure 5: (A) L.M of Group A after 6 weeks (TT) showing remarkable immature bone formation marked by increased number of osteocytes (arrows). Note the few Haversian systems among the woven bone (arrowheads). (H\&E x 100). (B) L.M of Group A after 6 weeks (IT) showing increased amount of mature bone. Note the evident zones of immature bone with enlarged blood vessels (arrows). (H\&E x 100). (C) L.M of study group after 6 weeks (CT) showing mature bone. Note the well-developed haversian systems (arrows). (H\&E x 100)

\section{Group B:}

TT: The osteotomy line was mainly filled with irregularlyarranged woven bone, which was intermingled with large islands of mature bone. However, areas of dense granulation tissue rich in blood vessels were seen interrupting the bone continuity at the fracture line. Newly-formed bony spicules were detected within this fibrous condensation (Figure 6A).

IT: The fracture site contained a combination of mature and immature bone, with medium-sized areas of vascular connective tissue (Figure 6B).

CT: The osteotomy gap was filled with a combination of woven and mature bone. However, small-sized and medium-sized bone marrow spaces filled with fibrous tissue and engorged blood vessels were noticed (Figure 6C).

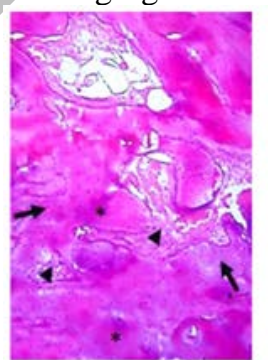

A

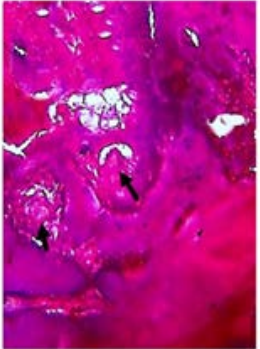

B

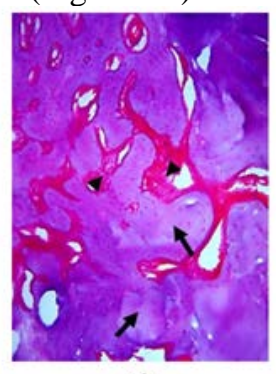

C
Figure 6: (A)L.M of Group B after 6 weeks (TT) showing considerable amount of immature bone formation marked by increased number of osteocytes (arrows), intermingled with discrete areas of mature bone (stars). Note the evident zones of granulation tissue with enlarged blood vessels (arrowheads). (H\&E x 100). (B) L.M of Group B after 6 weeks (IT) showing increased amount of immature bone containing medium-sized marrow spaces filled with vascularized connective tissue (arrows). (H\&E x 100). (C) L.M of Group B after 6 weeks (CT) showing evident islands of mature bone (arrows), enclosing limited zones of fibrous tissue (arrowheads). (H\&E x 100) 


\section{Histomorphometric and Statistical Analysis}

The percentages of newly formed bone in the different observation periods ( 2 and 6 weeks) in the group A and group B and thirds (TT, IT and CT) are presented in table 1. Two-way ANOVA demonstrated a statistically significant difference among the all thirds (p3 $<0.001)$ at 2 weeks between the two groups. At 6 weeks, there were no statistically significant differences between the two groups among the TT and CT but there was a statistically significant difference ( $\mathrm{p} 4=0.039)$ in the IT.

The test showed a statistically significant difference for time points more specifically, there was a higher percentage of newly formed bone at 6 weeks compared with that at 2 weeks.

Table (1): Relation between the four groups according to the percentage of newly formed bone among the TT, IT and CT between Group A and Group B.

\begin{tabular}{|c|c|c|c|c|c|c|}
\hline & \multicolumn{2}{|c|}{ Group A } & \multicolumn{2}{|c|}{ Group B } & \multirow[b]{2}{*}{$\mathbf{F}$} & \multirow[b]{2}{*}{$\mathbf{p}$} \\
\hline & $\begin{array}{c}2 W \\
(n=3)\end{array}$ & $\begin{array}{c}6 W \\
(n=3)\end{array}$ & $\begin{array}{c}2 W \\
(n=3)\end{array}$ & $\begin{array}{c}6 W \\
(n=3)\end{array}$ & & \\
\hline \multicolumn{7}{|l|}{ TT } \\
\hline Min. - & $21.66-$ & $89.28-$ & $12.74-$ & $88.06-$ & & \\
\hline Max. & $\begin{array}{c}24.92 \\
23.61+\end{array}$ & 92.07 & $\begin{array}{c}13.22 \\
13.03+\end{array}$ & $\begin{array}{c}51.10 \\
8986+\end{array}$ & 1726.29 & \\
\hline$\pm \mathrm{SD}$ & 1.72 & 2.53 & 0.26 & 1.61 & & \\
\hline $\begin{array}{r}\text { Media } \\
n\end{array}$ & 24.24 & 91.08 & 13.13 & 90.33 & & \\
\hline $\begin{array}{l}\text { Sig. bet. } \\
\text { grps. }\end{array}$ & \multicolumn{4}{|c|}{$\mathrm{p}_{2}<0.001^{*}, \mathrm{p}_{3}<0.001^{*}, \mathrm{p}_{4}=0.997$} & & \\
\hline \multicolumn{7}{|l|}{ IT } \\
\hline $\begin{array}{l}\text { Min. - } \\
\text { Max. }\end{array}$ & $\begin{array}{c}29.47- \\
31.74\end{array}$ & $\begin{array}{c}96.09- \\
99.18\end{array}$ & $\begin{array}{c}17.80- \\
18.72\end{array}$ & $\begin{array}{c}90.63- \\
95.0\end{array}$ & & \\
\hline $\begin{array}{l}\text { Mean } \\
\pm \text { SD }\end{array}$ & $\begin{array}{c}30.53 \pm \\
1.14\end{array}$ & $\begin{array}{c}97.23 \pm \\
1.69\end{array}$ & $\begin{array}{c}18.12 \pm \\
0.51\end{array}$ & $\begin{array}{c}93.02 \pm \\
2.21\end{array}$ & $\underset{*}{2182.95}$ & $<\underset{*}{0.001}$ \\
\hline $\begin{array}{c}\text { Media } \\
\mathrm{n}\end{array}$ & 30.38 & 96.43 & 17.86 & 93.42 & & \\
\hline $\begin{array}{l}\text { Sig. bet. } \\
\text { grps. }\end{array}$ & \multicolumn{4}{|c|}{$\begin{array}{c}\mathrm{p}_{1}<0.001^{*}, \mathrm{p}_{2}<0.001^{*}, \mathrm{p}_{3}<0.001^{*}, \\
\mathrm{p}_{4}=0.039^{*}\end{array}$} & & \\
\hline \multicolumn{7}{|l|}{ CT } \\
\hline $\begin{array}{l}\text { Min. - } \\
\text { Max. }\end{array}$ & $\begin{array}{c}37.01- \\
38.20\end{array}$ & $\begin{array}{c}95.42- \\
99.43\end{array}$ & $\begin{array}{c}19.04- \\
20.48\end{array}$ & $\begin{array}{c}91.74- \\
97.95\end{array}$ & 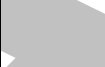 & \\
\hline $\begin{array}{l}\text { Mean } \\
\pm \text { SD. }\end{array}$ & $\begin{array}{c}37.65 \pm \\
0.60\end{array}$ & $\begin{array}{l}96.96 \pm \\
2.16\end{array}$ & $\begin{array}{c}19.83 \pm \\
0.73\end{array}$ & $\begin{array}{c}95.62 \pm \\
3.38\end{array}$ & $\underset{*}{1111.13}$ & \\
\hline $\begin{array}{r}\text { Media } \\
n\end{array}$ & 37.74 & 96.04 & 19.98 & 97.17 & & \\
\hline $\begin{array}{l}\text { Sig. bet. } \\
\text { grps. }\end{array}$ & \multicolumn{4}{|c|}{$\begin{array}{c}\mathrm{p}_{3}<0.001^{*}, \mathrm{p}_{1}<0.001^{*}, \mathrm{p}_{2}<0.001^{*}, \mathrm{p}_{4}=0.8 \\
53\end{array}$} & & \\
\hline
\end{tabular}

F: F for ANOVA test, Pairwise comparison between each 2 groups was done using Post Hoc Test (Tukey)

p1: p value for comparing between GA- $\mathbf{2 W}$ and GA-6W p2: p value for comparing between GB- $\mathbf{2 W}$ and GB-6W p3: p value for comparing between GA- $\mathbf{2} \mathbf{W}$ and GB- $\mathbf{2} \mathbf{W}$ p4: p value for comparing between GA- $\mathbf{6 W}$ and GB-6W *: Statistically significant at $\mathrm{p} \leq 0.05$

\section{DISCUSSION}

A variety of different treatment methods for mandibular fractures have been described. The key to successful management of these fractures is to understand the principles of the accurate reestablishment of occlusion, fracture reduction, and stable internal fixation (23).

Direct bone repair in the mode of contact healing did not take place in the experimental conditions used, as was infrequently found by Freitag and Landau in the year 1996, who reported such a pattern of bone repair as being confined to focal areas. Nevertheless, important endosteal and periosteal reactions were noticed adjacent to the osteotomy site at 2 weeks, which was characterized by immature, woven bone. Such a new bone formation progressively increased at 6 weeks in the three thirds (24).

The present study was conducted on twelve healthy dogs. In each dog, an iatrogenic osteotomy was performed between the mandibular 3rd and 4th premolars through an intra-oral approach using a surgical micro-reciprocating saw. The surgical blade was positioned perpendicular to the mandibular body and a complete defect will be created. The fragments was reduced bimanually and stabilized with the 3D miniplates in six dogs and the conventional miniplates in six dogs. These dogs were euthanized at 2 and 6 weeks postoperatively for histological evaluation of the healing process.

Only male dogs were used in our study to exclude any effects of female sex hormones on the structure, calcification and healing process of the bone. The main method of evaluation used in this study was the histological evaluation, which remains the most reliable method to determine the steps of new bone formation.

In the year 1989, Mckibbin mentioned that bone tissue has two remarkable properties that distinguish it from other structural material: it can alter its mechanical characteristics in response to changes in functional demand, and it also has the capacity to heal itself through a healing process resulting not in a scar, but in an actual reconstitution of the injured tissue (25). This healing process is affected by many variables, including the extent of damage to soft and hard tissue and the vascular supply caused by both the fracture and the fracture treatment (26).

Our study lasted for 6 weeks, and was divided into two time intervals 2 weeks and 6 weeks, in order to closely monitor the stages of the regeneration process. After each interval, six dogs were euthanized and the defect sites were processed and submitted for histological examination.

Farmand emphasized in his results the decrease in fixation material needed to stabilize the fracture and that no patient required additional fixation for fracture stabilization (6). The 3-D mini plates itself was a misnomer as the plates themselves were not 3 dimensional, but holds the fracture segments rigidly by resisting the 3 dimensional forces namely shearing, bending and torsional forces occurring on the fracture site in function (27).

Regardless of the IF system applied, the gap created by osteotomy was completely filled with newly formed bone by the end of the second experimental period. For both the two groups, the TT, IT and CT shared histological features, with the exception of the presence of the mandibular canal in the CT. The bone edges created by the osteotomy were connected by compact parallel-fibred bone exhibiting areas of both immature and lamellar bone and Haversian canals of varying diameter. Although the osteotomy site was completely filled with parallel-fibred bone, with more newly formed Haversian systems in Group A compared with Group B, such a stage of bone repair did not reach the typical aspects of the parent lamellar bone.

On the basis of this study, we can conclude that 3D plate is an alternative approach with a similar outcome profile to miniplates. This finding was in accordance with the clinical work of Budhraja, et al.: 3-D plate versus conventional miniplates (27). 
The study generated evidence that the 3D plates are more effective compared to conventional for the fixation mandibular fractures. Thus, three dimensional miniplates are more effective compared to conventional miniplates according to the results of Sadhwani and Anchlia: 2d v/s 3d plates in mandible fractures $(28,29)$. 3D plates should be preferred over conventional miniplates for the treatment of mandibular fracture. This produced the improved outcomes in terms of ideal molar relationship, decrease fracture mobility and anatomic reduction (30)

\section{CONCLUSION}

Based on the above, it can be concluded that 3-D plates could be a better option than conventional 2-mm miniplates. The small sample size and limited follow-up could be considered as the limitations of this study.

\section{CONFLICT OF INTEREST}

The authors declare that they have no conflicts of interest.

\section{REFERENCES}

1-Connolly JF, Hahn H, Davy D. Fracture healing in weightbearing and nonweight-bearing bones. J Trauma. 1978; 18:766-70.

2-Spiessl B. Rigid internal fixation of fractures of the lower jaw. Reconstr Surg Traumatol. 1972; 13:124.

3-Champy M, Pape H, Gerlach K, Lodde J. The Strasbourg miniplate osteosynthesis. Oral Maxillofac Traumatol. 1986; 2:19-43.

4-Michelet FX, Deymes J, Dessus B. Osteosynthesis with miniaturized screwed plates in maxillo-facial surgery. J Maxillofac Surg. 1973; 1:79-84.

5-Cawood J. Small plate osteosynthesis of mandibular fractures. Br J Oral Maxillofac Surg. 1985; 23:77-91.

6-Farmand M, Dupoirieux L. The value of 3-dimensional plates in maxillofacial surgery. Rev Stomatol Chir Maxillofac. 1992; 93:353-7.

7-El Nakeeb N, Shokry M, El Dibany M. A comparative study between 3-D plates and conventional miniplates for internal fixation of anterior mandibular fractures. ADJ. 2016; 41:253-60.

8-Guimond C, Johnson JV, Marchena JM. Fixation of mandibular angle fractures with a 2.0-mm 3-dimensional curved angle strut plate. J Oral Maxillofac Surg. 2005; 63:209-14.

9-Zix J, Lieger O, Iizuka T. Use of straight and curved 3dimensional titanium miniplates for fracture fixation at the mandibular angle. J Oral Maxillofac Surg. 2007; 65:1758-63.

10-Kalfarentzos EF, Deligianni D, Mitros G, Tyllianakis M. Biomechanical evaluation of plating techniques for fixing mandibular angle fractures: the introduction of a new 3D plate approach. J Oral Maxillofac Surg. 2009; 13:139-44.

11-Vineeth K, Lalitha R, Prasad K, Ranganath K, Shwetha V, Singh J. A comparative evaluation between single noncompression titanium miniplate and three dimensional titanium miniplate in treatment of mandibular angle fracture: A randomized prospective study. J Oral Maxillofac Surg. 2013; 41:103-9.

12-Reichert JC, Saifzadeh S, Wullschleger ME, Epari DR, Schütz MA, Duda GN, et al. The challenge of establishing preclinical models for segmental bone defect research. Biomaterials. 2009; 30:2149-63.
13-Schimandle JH, Boden SD. Spine update. The use of animal models to study spinal fusion. Spine. 1994; 19:1998-2006.

14-Pearce A, Richards R, Milz S, Schneider E, Pearce S. Animal models for implant biomaterial research in bone: a review. Eur Cell Mater. 2007; 13:1-10.

15-Aerssens J, Boonen S, Lowet G, Dequeker J. Interspecies differences in bone composition, density, and quality: potential implications for in vivo bone research. Endocrinology. 1998; 139:663-70.

16-Müller ME, Allgöwer $M$, Allgower $M$, Schneider R, Willenegger $\mathrm{H}$. Manual of internal fixation: techniques recommended by the AO-ASIF group. Berlin: Springer Science \& Business Media; 1991.

17-Urist MR, Peltier LF. Bone: Formation by Autoinduction. Clin Orthop Relat Res. 2002; 395:4-10.

18-Priemel M, von Domarus C, Klatte TO, Kessler S, Schlie J, Meier S, et al. Bone mineralization defects and vitamin D deficiency: Histomorphometric analysis of iliac crest bone biopsies and circulating 25-hydroxyvitamin D in 675 patients. J Bone Miner Res. 2010; 25:305-12.

19-Ferreira T, Rasband W. Image J user guide. ImageJ/Fiji 1.46. 2012. Available at: https://imagej.nih.gov/ij/docs/guide/user-guide.pdf.

20-Siegenthaler A, Mondal D, Benvenuto C. Quantifying pigment cover to assess variation in animal colouration. Biology Methods and Protocols. 2017; 2:1-8.

21-Feeney BC, Kirkpatrick LA. A simple guide to IBM SPSS statistics for version 20.0. 12th ed. Australia, Brazil: Wadsworth Cengage learning; 2012.

22-Kotz S, Johnson NL. Encyclopedia of statistical sciences. Hoboken, N.J.: Wiley Online Library; 1981.

23-Al-Moraissi EA, Ellis E. Surgical management of anterior mandibular fractures: a systematic review and metaanalysis. J Oral Maxillofac Surg. 2014; 72:2507.e1-e11.

24-Freitag V, Landau $\mathrm{H}$. Healing of dentate or edentulous mandibular fractures treated with rigid or semirigid plate fixation-an experimental study in dogs. J Craniomaxillofac Surg. 1996; 24:83-7.

25-McKibbin B. The biology of fracture healing in long bones. J Bone Joint Surg Br. 1978; 60:150-62.

26-Rasubala L, Yoshikawa H, Islam A, Nagata K, Iijima T, Ohishi M. Comparison of the healing process in plated and non-plated fractures of the mandible in rats. $\mathrm{Br} \mathrm{J}$ Oral Maxillofac Surg. 2004; 42:315-22.

27-Budhraja NJ, Shenoi RS, Badjate SJ, Bang KO, Ingole PD, Kolte VS. Three-dimensional locking plate and conventional miniplates in the treatment of mandibular anterior fractures. Ann Maxillofac Surg. 2018; 8:73.

28-Gupte SH, Chaddva S, Jethwani Y, Mohandas A, Kumavat DP, Jhaveri N. Evaluation of Efficacy of Three-dimensional Stainless Steel Mini-Plates in the Treatment of Fractures of the Mandible: A Prospective Study. J Orthop Case Rep. 2016; 6:35-40.

29-Sadhwani BS, Anchlia S. Conventional $2.0 \mathrm{~mm}$ miniplates versus 3-D plates in mandibular fractures. Ann Maxillofac Surg. 2013; 3:154.

30-Ali Z, Shakeel J, Furqan M. Mandibular symphysis fractures; comparison of conventional mini plates versus 3d mini plates in the fixation of isolated mandibular symphysis fractures in abbasi shaheed hospital karachi--a clinical study. Professional Med J. 2018; 25:815-22. 